\title{
TEACHERS' ENGAGEMENT WITH WORK AND THEIR PSYCHOLOGICAL WELL-BEING
}

\author{
Dzintra Iliško \\ Daugavpils University, Latvia \\ Jeḷena Badjanova \\ Daugavpils University, Latvia \\ Svetlana Ignatjeva \\ Daugavpils University, Latvia
}

\begin{abstract}
A number of studies are focusing on interrelations that exist between teachers' subjective well-being and financial well-being, occupational stress and other factors that influence teachers' happiness at work. The aim of this study is to explore the factors influencing teachers' psychological well-being. This involves teachers' engagement with their professional development. Psychological well-being is conceptualized as a psychological state of mind of teachers in balancing expectations and ability to meet those requirements, a desire for a mindful and meaningful involvement with their work, as well as resilience and competency to deal with the challenging requirements at the workplace. Teachers' well-being and happiness at work positively influences their performance and a well-being of pupils as well. As a rule, teachers' profession is associated with high stress, heavy workload, high demands on management in the classroom, high demands on pupils' academic achievements, and the additional pressure placed on teachers' engagement with further education. The authors carried out a questionnaire among the teachers from Latvia $(n=247)$. They filled in a questionnaire on a voluntary basis about their subjective well-being in relations to their involvement with the pedagogical work. The authors explored correlation between teachers' engagement with the research, their educational level, involvement in administrative work, teachers' personal growth, their view on pupils as open systems and their well-being. It was concluded that all teachers who took part in this study is a relatively homogenous group. Considering their diverse experience of work, educational level and involvement with the scientific and administrative work, their psychological wellbeing can be evaluated higher as average.
\end{abstract}

Keywords: teachers' psychological well-being, satisfaction at work, resilience.

\section{Introduction}

The aim of this study is to explore the factors that determine teachers' psychological well-being. The topicality of this study is determined by growing demands placed on teachers' job and by the reform processes on all levels of education towards implementing a competency based approach in education. 
This causes quite a high level of stress and burnout among teachers. This requires teacher trainers to provide teachers with the tools and strategies necessary for developing resilience in dealing with the reform based transitions in education.

The research methodology designed for the purpose of this study is a questionnaire with the aim to measure teachers' well-being and the analyses of the data gained in the questionnaire. The sample is comprised of two hundred forty-seven teachers representing all age groups who were asked to fill in a questionnaire on a voluntarily bases in both paper format and in an electronic version. The questionnaire was originally designed by Carol Ryff (1989) and was adopted for the Latvian context.

\section{Teachers’ Psychological Well-Being Defined}

Well-being is a complex term that is difficult to define (Pollard \& Lee, 2003). This makes it difficult for the researchers to design the scale to measure teachers' well-being. Dodge et al. (2012) proposes a new definition of a wellbeing as "the balance point between an individual's resource pool and the challenges they face” (p.230). Resource pool includes one's socio economic status, psychological factors, and beliefs about one's competency equipping the person to adapt the resources in order to gain his or her well-being.

One of the determining factors of teachers' well-being in relation to a professional field of work is teachers' qualification and continuous upgrading of their knowledge. The determining factors of success of teachers at work can be explained/strengthened with the best practice from the Finish educational system where the main emphases is placed on high certification of teachers gained in the research and professionally oriented master's programs that ensure high qualification of teachers (Toom et al, 2000). Deep learning allows teachers to integrate new resources and knowledge into the existing schemes of knowledge and strengthens teachers' ability to reflect on their values, strength and weaknesses, as well as on obstacles and aspiration.

As Folmann (1984) states, teachers' professional stress results from teachers' perception that they cannot cope with the new situation at work since they do not have sources to deal with it. This leads to a burnout, chronic fatigue, cynicism and indifference (Heikkila et al., 2012). Paterson \& Grantham (2016) suggests ecological view on teachers' well-being based on Bronfenbrenner's (1979) model that takes into account environmental, social, political and economic factors that influence teachers' well-being.

The concept of a well-being is closely related to teachers' physical fitness. Fitness attributes include social, emotional, spiritual and cognitive dimensions, namely, alignment with teachers' health, happiness and energy reserves (Price \& 
McCallum, 2014). The authors conclude that by reflecting on peaks and obstacles of a well-being trajectory of teachers, one can discover the factors that influence those patterns that determine teachers' capacity for resilience in the midst of the reform process and their ability to undertake agency.

Age is another factor that influences teachers' well-being that was included as one of the factors in the questionnaire. Senior teachers differ from the younger ones due to their biological, mental and social characteristics, since their physical and intellectual resources decrease with their age. Aging is also associated with a burnout and emotional exhaustion of teachers. The supportive relationships can help to cope with a burnout (Sottimano, Guidetti, Converso, \& Viotti, 2018). The age can be both, a priority because of teachers' practical wisdom and skills to cope with the professional stress and the obstacle in the process of introducing innovations and technologies in the classroom practice. There are numerous interventions aimed at enhancing teachers' well-being. One of them is a compulsory further education and training seminars for teachers.

Roeser et al. (2012) relate teachers' psychological well-being with teachers' mastery of classroom management skills, ability to control their emotions and skills in dealing with stress. They refer to mindfulness in developing teachers' resilience and ability to deal with stress inside and outside the classroom. As Jennings (2015) asserts, mindful teacher will be able to regulate their emotions, solve power struggles with their students more constructively and to build more constructive relations. Mindfulness training also involves teacher's ability to accept uncertainty, develop their enhanced awareness of the present moment that can improve their well-being.

\section{Research Methodology}

For the purpose of this research the authors have used the scale of psychological well-being designed by Carol Riff (1995). The questionnaire was adapted in both, Russian and Latvian version from the English-language "Scales of psychological well-being” by Carol Riff. The questionnaire was validated several times in various versions. The questionnaire "Scales of psychological well-being" by Carol Riff is a theoretically substantiated tool and is designed to measure the main components of teachers' psychological well-being. Currently, the multidimensional model of Carol Riff is accepted by many researchers, and the methodology developed by her for measuring psychological well-being is actively used by the scientists in many countries. This technique measures actual psychological well-being in contrast to a potential well-being. The concept is derived from the humanistic paradigm, but is not currently operationalized by any questionnaire. For the purpose the authors adopted a version of Ryff's questionnaire adapted by Shevelenkova and Fesenko (2005) that focuses on 
three factors: the meaning in one's life, setting the goals in one's life, and a view of a person as an open system.

\section{Research Participants}

The number of teachers who took part in this research were $n=247$ teachers, from whom 169 were married and 78 claimed themselves single. The average age of participants was 37 (Mean=10.98, SD=12). Questionnaire data included such parameters as age, education, teachers' involvement in the scientific work, participation in the research, and other scientific activities.

$71 \%$ of all participants work in the school setting, $15,4 \%$ of them work in the field of a vocational education, and $13,4 \%$ of them work in the secondary school setting. $57 \%$ of all the respondents who took part in the questionnaire completed bachelor studies, while $42 \%$ of them were enrolled as students in Master's program. 44\% of them were engaged only in teaching, while $33,6 \%$ of all participants were engaged only in administrative work, and $79 \%$ of them were not involved in any scientific work.

\section{Research Results}

By the use of SPSS operating system, two factor analyses were carried out and all teachers who participated in this research were divided in three cluster groups. There were no significant differences discovered among the participants of those three groups.

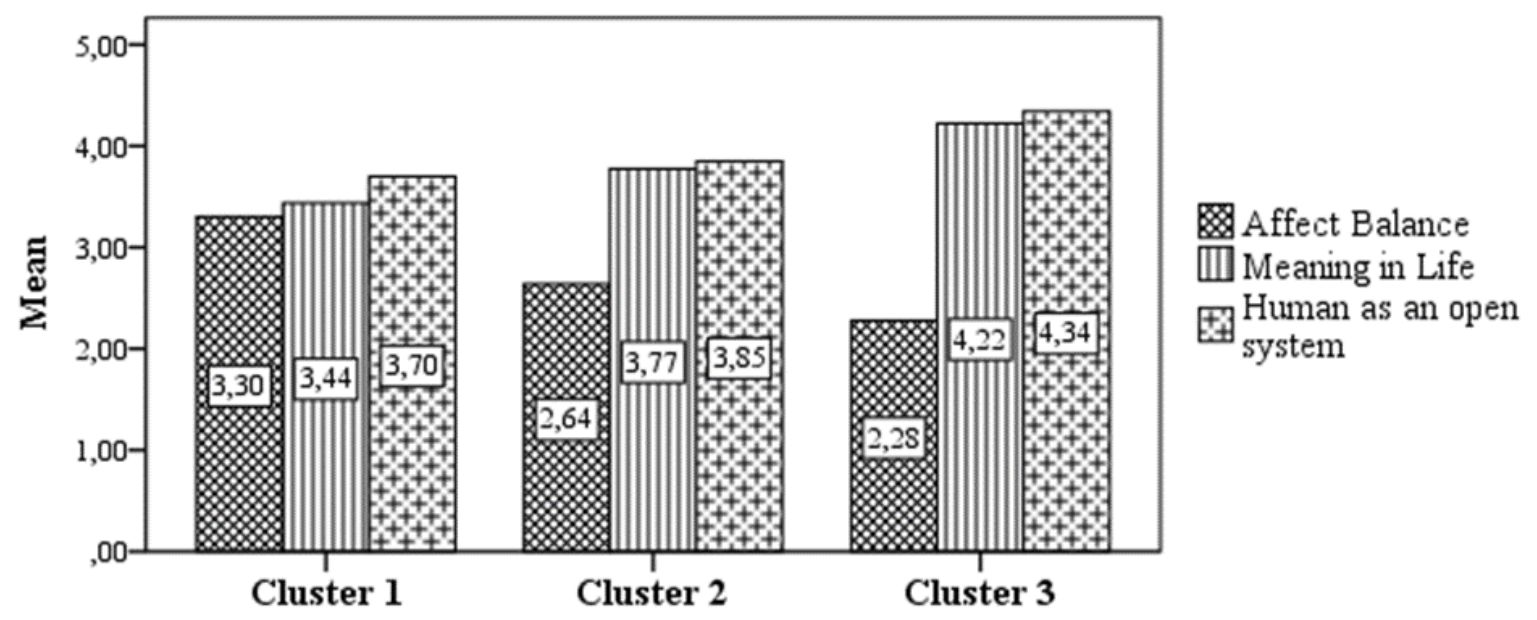

Figure 1 Three groups of clusters of teachers

All three groups of teachers' form quite a homogeneous groups of respondents with having only slight differences. Their level of a psychological well-being is above average according to the Likert's five-point scale. The 
highest indicators are in the third cluster group among the teachers who see the highest meaning of their lives. They are involved in teaching in the comprehensive school setting at the secondary school stage, and $23 \%$ of them are involved in scientific activities. The teachers from the $3^{\text {rd }}$ cluster group see and treat themselves and pupils as an open system and have much higher meaning of life as compared with the teachers from the first cluster group of participants, but all other criteria the level of teachers' well-being the teachers from all cluster groups are still above the average. Despite of teachers complains about the stress caused by the constantly changing demands and the reform processes, accompanied by a burnout, their actual level of psychological wellbeing is above the average.

The data gained in the questionnaire also indicate that the teachers with a higher level of education have a higher level of psychological well-being (see Figure 2).

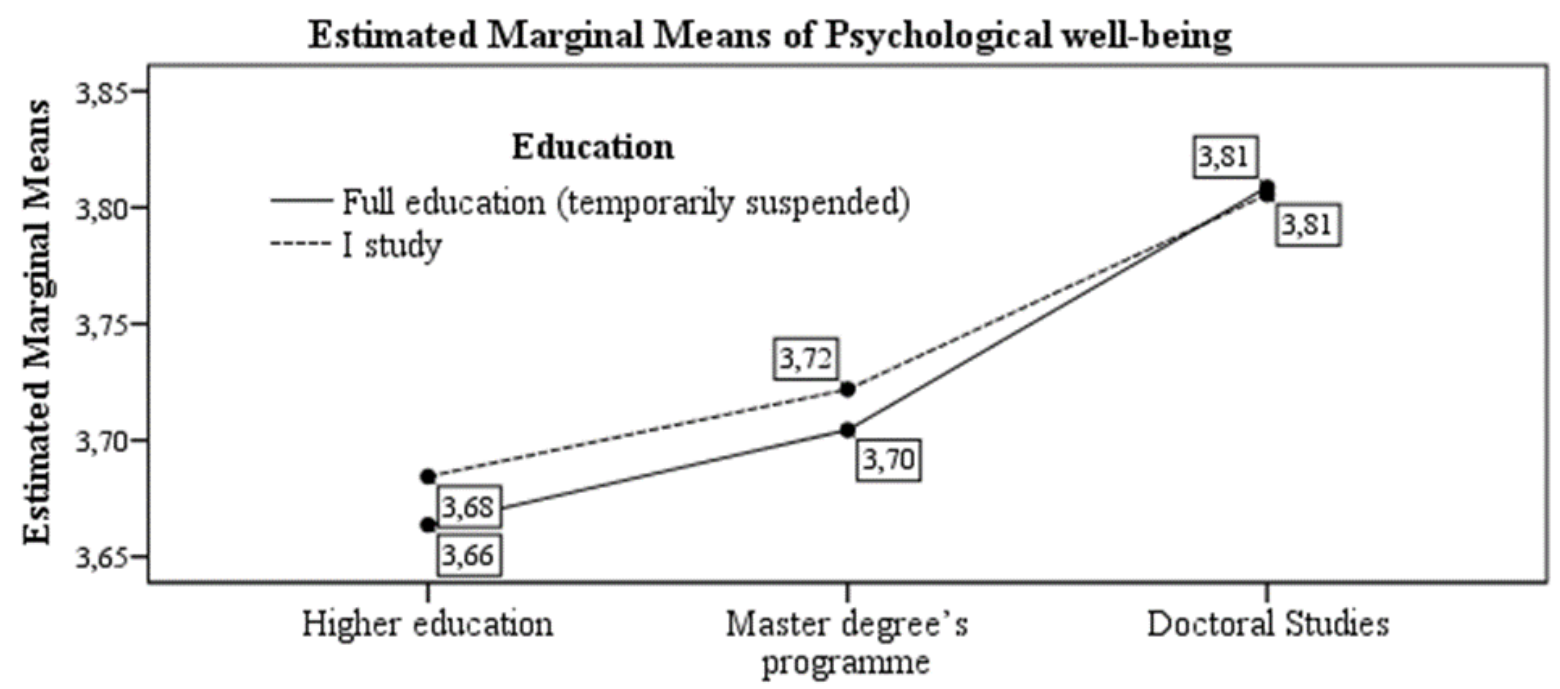

The level of education (finished or received)

Figure 2 Teachers' psychological well-being and their level of education

Data gained in this questionnaire allows one to conclude that education to some degree influences teachers' well-being. One can observe a clear correlation between teachers' level of education and their ability to set goals in their life (See Figure 3) 


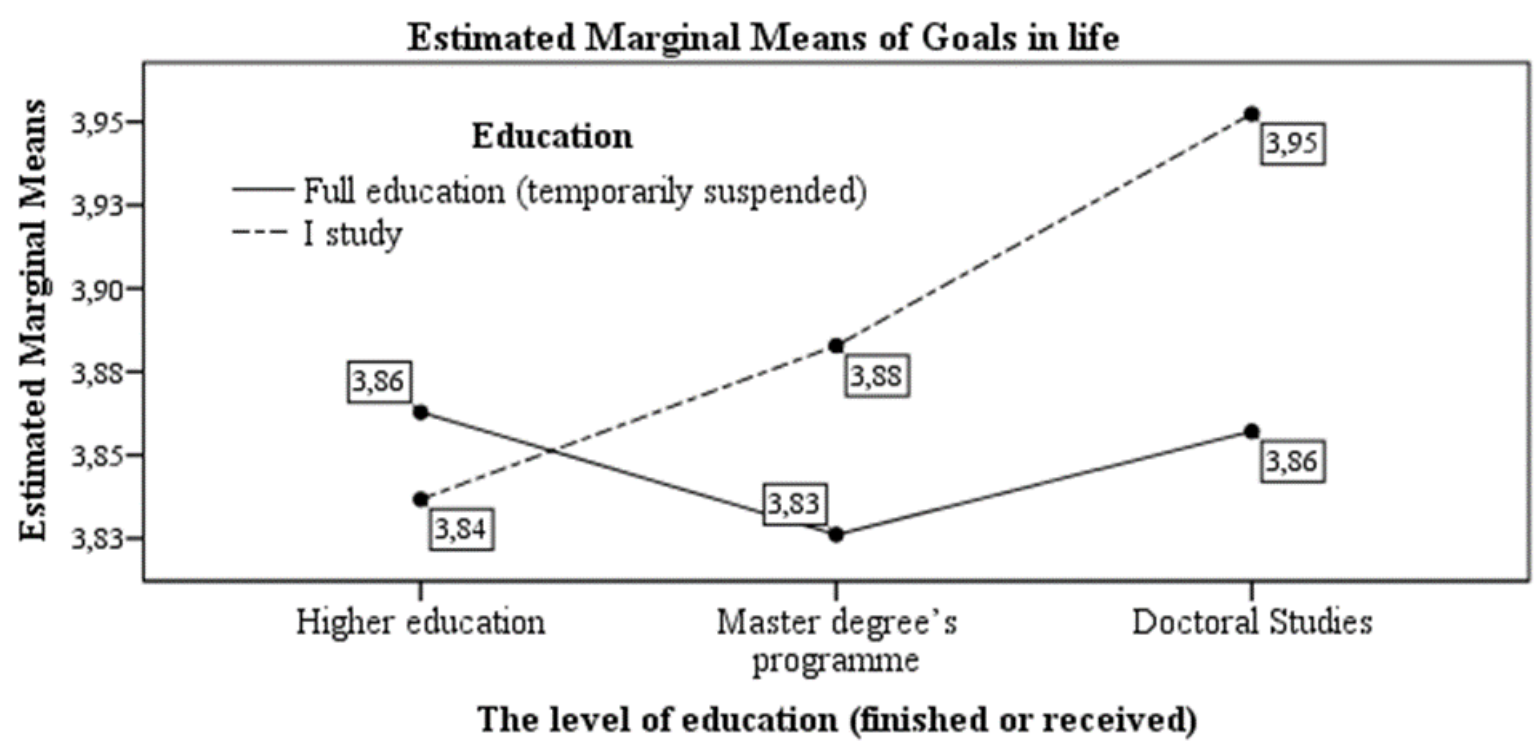

Figure 3 Teachers' psychological well-being and the goal setting in teachers' life

The higher is teachers' level of education, the higher is the goal and the purpose of their lives, while, the higher is their education, the more critical and skeptical teachers are towards processes in education and in the society (See Figure 4).

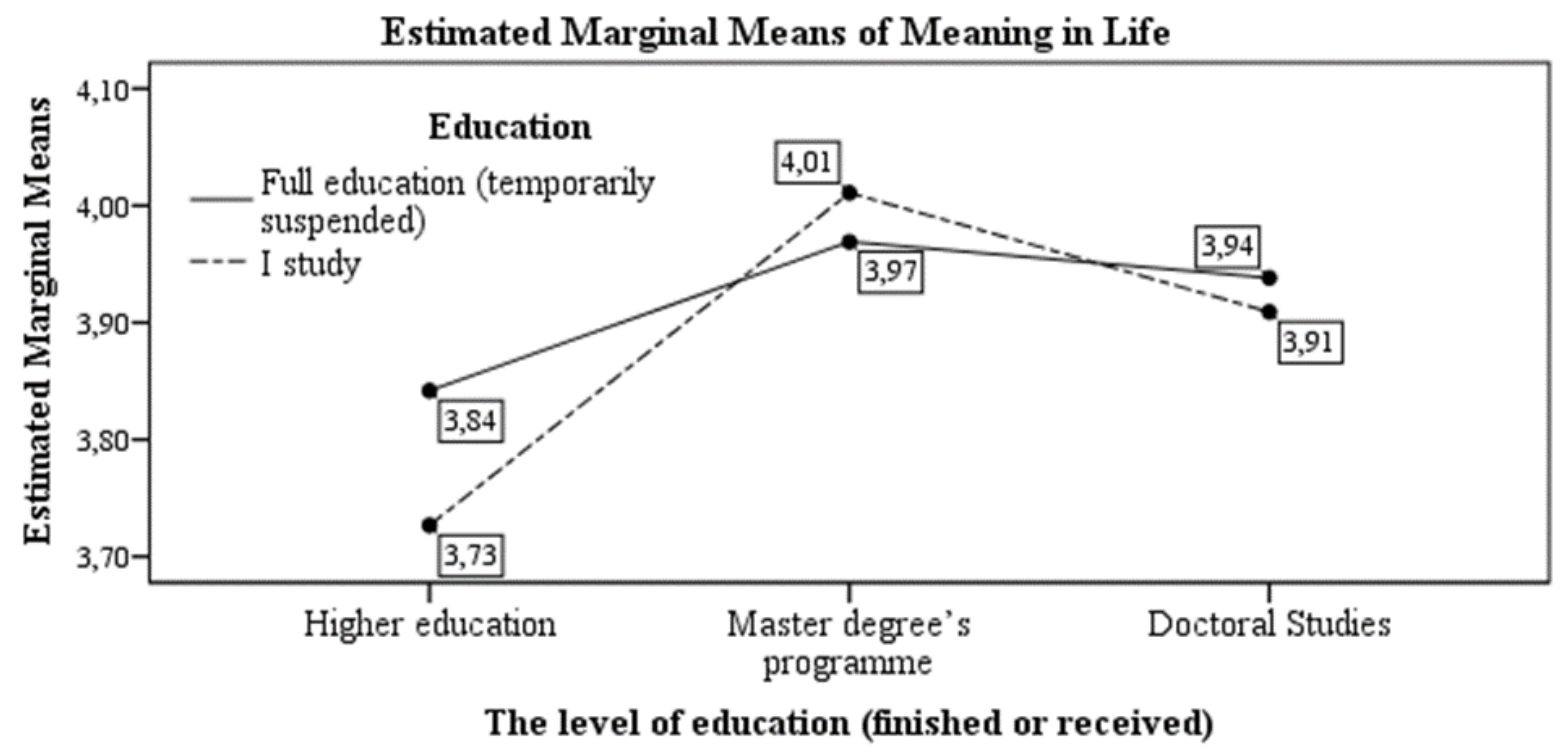

Figure 4 Teachers' psychological well-being and the meaning of life

There are number of coping strategies that teachers can adapt for building higher levels of well-being in their professional and personal life. Among them are cognitive coping strategies such as planning, mastery that predict a higher academic outcomes and leads to lower levels of stress, as well as action coping 
strategies, such as taking action in dealing with complex educational issues, and mastering competency at the workplace. This involves ongoing critical reflection on a complex and dynamic process of work which entails making sense of one's values and experience. The school management team needs to foster teachers' sense of ownership of their work. If teachers see the meaning in work and life, and feel valued and supported, they are more engaged in their work and produce quality outcomes. Such teachers are more resilient and capable of adapting to change (Dodge \& Gu, 2010; Mansfield, Beltma, Broadley, \& Weatherby-Fell, 2016).

\section{Implication for Teacher Trainers}

Pupils' and teachers' well-being are interrelated. Teachers' happiness and work is directly reflected in pupils' wellbeing. The focus on many studies has been placed on teachers' ability to cope with stress caused by the internal and external pressures. In order to provide a proper support for the teachers to build their resilience, there is a need for an in-depth study of specific context of the educational, social and organizational pressures placed upon teachers.

The acquired knowledge on teachers' psychological well-being will help teacher trainers to offer teachers tools for building their resilience in reform processes that are taking place in Latvia.

The best ways of building teachers' resilience to internal and external pressures caused by the educational reform processes in Latvia, is to develop supporting school's environment as a way of building teaches' resiliency to cope with the complexities in their work.

Teachers' well-being involves their autonomy at work, trust, commitment at work, and efficacy at work, and need to be seen in relation with the demands of the external environment as well. Number of scientists encourage focusing on teachers' strength, such as open mind, critical thinking and caring for other people, and oneself. Among the other factors of teachers' resilience Mansfield, et al. (2016) have mentioned personal resources (optimism, initiative, sense of vocation and mission, motivation, hope); contextual resources (colleagues, mentors, social networks, emotional support, collaboration); such strategies as (work-life balance, professional lifelong learning, time management, goal setting and mindfulness), as well as outcome factors (agency, job satisfaction, responsibility, passion, responsibility).

Teachers work involves multiple relations and how teachers interact and make sense of those relations while interacting with a wider social and cultural community. Teacher needs to be aware of "the fabric of resiliency building possibilities” (Henry \& Milstein, 2006). In the reform processes in Latvia towards competency based learning teachers need to become critically reflective 
practitioners who learn new practices, unlearn old assumption and shape their professional growth by developing resilience to all pressures that allow them to maintain enjoyment, motivation, commitment and enthusiasm for their work.

\section{Conclusions}

Teachers' psychological well-being is seen as multidimensional concept, including cognitive, affective, and behavioral dimensions. Since teaching is regarded as the most stressful occupation according to numerous studies (Jarvis, 2002), it is quite often accompanied by a burnout that in turn negatively impacts teachers' performance. This causes teachers' low commitment at work, low selfefficacy, low satisfaction at their workplace, and other psychosomatic complains. Within the last decade, a considerable attention has been paid to teachers' well-being and intervention strategies in order to build teachers' resilience in finding a balance in their work and life.

Teachers' well-being has been studied abundantly. Teachers with a high level of well-being see meaning in their work and life, make healthier choices and lead healthy lifestyle and they keep an open and sustainable view of a child and on future. The purpose of this study was to explore the well-being of teachers in Latvia who are required to reorient their teaching practice towards a competency based approach in education. There is a lot of ambiguity and uncertainty in the process of implementing new approach that causes stress and tension among teachers.

For the purpose of this study the authors chose the Ryff's (1995) model of psychological well-being that presents multidimensional framework of positive psychological wellbeing. It includes such dimensions of teachers' well-being as self-acceptance, autonomy, positive relationships, purpose of life and personal growth. Teachers who have a low level of well-being suffer from lower work commitment and a lack of concentration. Therefore, this is important to explore multiple aspects of teachers' wellbeing in order to propose intervention strategies.

This was concluded that all teachers who participated in this study form a relatively homogenous group. Teachers' psychological well-being can be evaluating as higher than average in different age groups, also among the teachers with different experience of work, educational level and engagement in the scientific work.

There is a correlation between the level of education of teachers and their ability to set positive goals in their life, although the higher is the level of their education, the more skeptical teachers become to unsustainable aspects of life and reform processes in Latvia that makes them become more inclined towards losing a meaning in their life. Still, they hold their pedagogical optimism and a 
view on their pupils as an open system. This gives hope to teachers to do their best in bringing forwards a more sustainable aim of education in the midst of reform processes in Latvia.

\section{References}

Day, C., \& Gu, Q. (2010). The new lives of teaches. UK: Routledge.

Dodge, R., Daly, A.P., Huyton, J., \& Sanders, L.D. (2012). The challenge of defining wellbeing. International Journal of Well-being, 2(3), 222-235.

Heikkila, A., Lonka, K., Nieminen, J., \& Niemivirta, M. (2012). Relations between teacher students' approaches to learning and attributional strategies, well-being and study success. Higher Education, 64, 455-471.

Henry, D., \& Milstein, M. (2006). Building leadership capacity through resiliency. Commonwealth council for leadership for educational administration and management, Lefcosia, Cyprus.

Jarvis, M. (2002). Teacher stress: A critical review of recent findings and suggestions for future research directions. Stress News, 14, 1-13.

Jennings, P.A. (2015). Mindfulness for teachers: Sample skills for peace and productivity in the classroom. New York: W. Norton.

Mansfield, C., Beltma, S., Broadley, T., Weatherby-Fell, N., (2016). Building resilience in teacher education: An evidenced informed framework. Teaching and Teacher Education, 77-87.

Paterson, A., \& Grantham, R. (2016). How to make teachers happy: An exploration of teacher wellbeing in the primary school context. Education \& Child Psychology, 33(2), 90-104.

Pollard, E., \& Lee, P. (2003). Child's well-being: A systematic review of literature. Social Indicators Research, 61(1), 9-78.

Price, D., \& McCallum, F. (2015). Ecological influences on teachers' well-being and 'fitness.' Asia-Pacific Journal of Teacher Education, 43(3), 195-209.

Roeser, R.W., Schonert - Reichl, A., Jha, M., Cullen, L., Wallace, R., Wilensky, R., Oberle, E. et al. (2012). Mindfulness training and reduction in teacher stress and burnout: Results from two randomized, waitlist-control field trials. Journal of Educational Psychology, 105(3), 787-804.

Ryff, C.D. (1989). Happiness is everything, or is it? Explorations on the meaning of psychological well-being. Journal of Personality and Social Psychology, 57, 10691081.

Ryff, C.D. (1995). Psychological well-being in adult life. Current Directions in Psychological Science, 4, 99-104.

Shevelenkova, T.D., \& Fesenko, P.P. (2005). Psychological well-being of the individual (A review of concepts and research methodology). Psychological diagnostics, 3, 95-129. 